\title{
Comprehensive Evaluation of Music Course Teaching Level Based on Improved Multi-attribute Fuzzy Evaluation Model
}

\author{
https://doi.org/10.3991/ijet.v15i19.17411 \\ Liuqing Yang \\ Henan Radio \& Television University, Zhengzhou, China \\ qingliuyang@126.com
}

\begin{abstract}
Aiming at the problems of multi-attribute fuzzy information and imperfect evaluation system existing in the current evaluation process of music course teaching level, the paper studies the multi-attribute fuzzy evaluation of music course teaching level, analyzes the influencing factors of music course teaching level, and establishes an improved music course teaching level evaluation system; then on this basis, combining with the fuzzy system theory, grey system theory and entropy weight method, it proposes a multi-attribute fuzzy evaluation model of music course teaching level to realize the quantitative analysis of music course teaching level, which has good engineering application value. At the same time, the paper also puts forward some strategies and suggestions to improve the teaching level of music courses, which are of good guidance and reference significance for improving the teaching quality of music courses.
\end{abstract}

Keywords-Music course, teaching level, comprehensive evaluation, multiattribute decision-making, fuzzy analysis.

\section{Introduction}

As an important part of modern education, music teaching is a key link in the implementation of quality education for students. A good music teaching implementation process not only has an indispensable supportive role for the improvement of professional knowledge and skills of music major students, but also plays a very important role in cultivating their comprehensive qualities and abilities [1-3]. However, because the teaching process of music courses is often affected by many factors, how to effectively improve the teaching level of music courses and scientifically evaluate and analyze the teaching level of music courses has gradually become the focus and difficulty in music teaching research [4-6]. To this end, some scholars have carried out a series of related studies and achieved constructive research results. For example: Firrincieli [7] researched and analyzed Maieutic, a teaching-learning method suitable for Western music. Marjanen and Cslovjecsek [8] studied a horizontal learning method in music teaching. Under the concept of the new curriculum standard, Wang [9] 
analyzed the problem of music pedagogical education for music teachers, and discussed the teaching methods, tools and evaluation systems of the cultivation of students' comprehensive abilities. Xu [10] conducted a preliminary discussion on the music teaching evaluation system. Sydykova et al. [11] discussed the cultivation of music teachers' creativity under modern education conditions. Kuloglu [12] explored an art teaching strategy for the basic education of music and design. Pan [13] analyzed the problems existing in the evaluation of general music teaching in colleges and universities and gave corresponding solutions.

However, current studies mostly focus on the analysis of music teaching implementation strategies or music course teaching level evaluation indicators, while for the processing of the fuzzy factors that may exist in music teaching implementation and evaluation, the discussion is not deep enough, and there're still rooms for further research of the systematicness, integrity, and comprehensiveness of the evaluation of music course teaching level. In view of this, based on an in-depth research on the influencing factors of music course teaching level, this paper comprehensively adopts fuzzy system theory, grey system theory, entropy weight method and other theories and methods to probe into a music course teaching level evaluation method based on the improved multi-attribute fuzzy evaluation model. This paper consists of 6 parts: the first part gives an overview of the current research on music course teaching level; the second part discusses the influencing factors in the implementation process of music course teaching; the third part establishes an improved music course teaching level evaluation system; the fourth part proposes a multi-attribute fuzzy evaluation model of music course teaching level; the fifth part gives a few suggestions and measures to promote the teaching level of music courses; the sixth part is the conclusion.

\section{Influencing Factors in the Implementation Process of Music Course Teaching}

\subsection{Educational appropriations for music course teaching}

Compared with other professional courses, the teaching of music courses not only requires to impart basic musical knowledge, but also needs to carry out a lot of practical teaching activities, which have an urgent demand for the equipment, environment, hardware design and software supporting facilities of music course teaching, especially in terms of pursuing details in music course teaching, it emphasizes more on the teaching quality and effects, therefore, the teaching of music courses requires good software and hardware conditions. Moreover, with the rapid development of modern intelligent technologies, some artificial intelligence technologies have been applied to the teaching of music courses, such as VR (virtual reality), multimedia, speech recognition, information technology, and computers, etc. The application of such technologies is very important for improving the quality of music teaching. To improve the hardware and software conditions of music course teaching, it is necessary to increase the educational appropriations for music teaching, so as to provide sufficient man- 
power, material and financial resources for the construction and reform of music course teaching.

\subsection{Faculty construction of music course teaching}

The teaching of music courses is a complex system project. In the process of music teaching, only one or a few music teachers are not enough to complete all the teaching tasks. Different music teachers have different abilities, knowledge, professional skills, background, teaching experience, and research directions; for the essence of music course teaching, they would have different perceptions, and their professional perspectives and research fields vary as well. Therefore, in order to improve the quality and efficiency of music course teaching, music professionals of multiple levels, professional directions and research fields are required; to exert their roles to a greater extent, they must be united into an organic whole, namely an integrated faculty team, only in this way can music course teaching achieve sustainable development and have strong competitiveness.

\subsection{Construction of management system for music course teaching}

The teaching process of music courses is affected and restricted by many influencing factors, including manpower, materials and finance, etc. At the same time, since the music course teaching process involves many aspects and links such as teaching goal formulation, scheme planning, syllabus writing, teaching plan preparation, teacher management, teaching activity management, teaching assistant management, teaching achievement management, and teaching performance assessment, if there isn't a good teaching management system to give instructions to these aspects and links, the teaching of music courses would be chaotic and disorderly, contradictions and problems may occur during the teaching process, resulting in that the teaching of music courses cannot be carried out normally, and the teaching tasks cannot be completed effectively, thereby affecting the quality and effects of music course teaching.

\subsection{Cultivation of music teachers' professional qualities and skills}

The learning of music courses not only requires acquiring the basic musical knowledge, but also needs to make lots of skill practice, and this process requires music teachers to have good professional qualities and skills. The professional qualities and skills of music teachers have a direct impact on the improvement of the teaching quality of music courses, especially in terms of music students' divergence of music theory thinking, improvement of innovation ability, and expansion of music perspectives, they will point out the right directions, give instructive references and provide technical supports, etc. If the entire music course faculty has higher professional qualities and skills, the teaching process and results of the music courses would achieve better effects; on the contrary, the teaching effects would be compromised. Therefore, enhancing the cultivation of music teachers' professional qualities and skills is of great significance. 


\subsection{Construction of quality music courses}

The preparation of teaching materials for music courses is the main embodiment of the construction of music courses, and the selection of teaching materials will directly determine the key knowledge to be lectured in each execution links during the implementation process of music courses. It can be seen that the application of music course materials has a great impact on the absorption of music knowledge, the cultivation of musical perspectives, the training of musical thinking, and the enhancement of musical innovation ability; in particular, as music knowledge has increasingly diversified types and forms, the music courses need more typical and excellent teaching materials. For this reason, it is necessary to pay more attention to the construction of high-quality music courses and form a series of excellent music course teaching materials with professional features, thereby providing an important support for the smooth implementation of music teaching.

\subsection{The social service and student management mechanism of music course teaching}

The goal of education is to cultivate knowledge-based talents that can meet the requirement of social development. Music education, as an important part of modern quality education, must cultivate music talents based on this requirement, that is, music teaching comes from the society, it must serve the society, as well as satisfy the social demand for music talents. Therefore, in the teaching process of music courses, attention should be paid to the integration of music teaching and social requirement, the closer the music teaching to the social requirement, the better it could promote the learning motivation of music students. At the same time, during music students' learning process, due to the diversity of individual students and the standardization of course teaching, it is necessary to manage the student group in a targeted manner, and clarify the corresponding reward-and-punishment mechanisms, so as to improve the learning motivation and interests of students, thereby achieving the purpose of enhancing students' learning effect.

\section{An Improved Evaluation System for the Teaching Level of Music Courses}

This paper holds that the improvement of the teaching level of music courses is affected by many factors. In order to ensure the systematicness, integrity, and comprehensiveness of the evaluation of the teaching level of music courses, this paper proposes an improved music course teaching level evaluation system, which mainly analyzes from the following four aspects: the teaching ability of music teachers, the learning ability of music students, the planning and management ability, and the teaching results. 


\subsection{Teaching ability of music teachers}

The aspect of the teaching ability of music teachers mainly investigates the course lecturing ability of music teachers during the implementation process of music courses, it's analyzed from three dimensions: the preparation of music teaching, the execution of teaching links, and the teaching effect and feedback. The main evaluation indicators of music teaching preparation include: the basic professional qualities and abilities of music teachers, the formulation of music course teaching schemes, the planning of music course teaching tasks, the application of music course textbooks, and the reserves of music teaching content. The main evaluation indicators of the execution of teaching links include: the systematicity and scientificity of the teaching content of music courses, the intelligence and practicality of teaching tools, the advancement and integration of teaching methods, the diversity and richness of teaching forms, the controllability of teaching process, the interactivity of classroom teaching, and the correctness of teaching attitude, etc. The main evaluation indicators of the music teaching effect and feedback include: the completion of music teaching tasks, the absorption of course content, and students' learning Q\&A, etc.

\subsection{Learning ability of music students}

The aspect of the learning ability of music students mainly investigates the students' learning status during the implementation process of music teaching, its evaluation indicators include: music students' performance in classroom discipline during the learning process, students' preview before music courses, classroom participation, the digestion of the key and difficult knowledge of music courses, homework completion, summarization of music course questions, and feedback and communication of music course questions, etc.

\subsection{Music course planning and management ability}

The aspect of music course planning and management ability mainly investigates the execution situations of teaching organization, teaching management, teaching reform and other links in the implementation process of music teaching. The evaluation indicators of music course teaching organization include: the selection of music course teaching materials, the planning of teaching goals, the construction of teaching organization framework, the implementation of teaching strategies, the formulation of teaching syllabus, and the formulation of teaching assessment standards. The evaluation indicators of music teaching management include: the perfection of music course teaching management system, the construction of hardware facilities, the upgrade of software system, the construction of talent team, and the construction of curriculum system, etc. The evaluation indicators of music teaching reform include: the improvement of music classroom teaching environment and atmosphere, the improvement of teaching ideas, the improvement of teaching modes, and the integration of teaching practice and scientific research, etc. 


\subsection{Music course teaching results}

The aspect of music course teaching results mainly investigates the teaching achievements of music courses in different implementation stages, which are specifically divided into the achievements in music teaching, students' achievements in music learning, and the achievements in music teaching management. The evaluation indicators of achievements in music teaching include pass rate, excellent rate, teaching satisfaction, students' participation in professional competitions, students' awards in professional competitions, etc. The evaluation indicators of students' achievements in music learning include: students' mastery of music knowledge and skills, cultivation of music students' learning methods, improvement of students' abilities in music innovation and development, improvement of students' abilities in music practice, and the improvement of students' independent learning abilities, etc. The evaluation indicators of the achievements in music teaching management include teaching awards, situation of teaching reform projects undertaken, introduction of senior talents, teaching reform awards, compilation of excellent course textbooks, publication of highquality papers, social satisfaction, etc.

\section{Multi-Attribute Fuzzy Evaluation Model of Music Course Teaching Level}

\subsection{Unified scale processing of evaluation indicators}

It can be seen from the construction process of the music course teaching level evaluation system that the different-level evaluation indicators generally cannot accurately describe the teaching level of music courses, that is, the magnitudes of the evaluation indicators are fuzzy and uncertain; moreover, since the evaluation indicators describe different evaluation contents, their scales are different as well, therefore, the evaluation indicators need to be subject to unified scale processing.

Assume there are $\mathrm{m}$ objects to be evaluated and $\mathrm{n}$ evaluation indicators, the initial value of the $\mathrm{i}$-th evaluation object with respect to the $\mathrm{j}$-th evaluation indicator is $V_{i j}=\left[v_{i j}(a), v_{i j}(b)\right], v_{i j}(a) \leq v_{i j}(b)$; if this indicator is a positive indicator, the value of the unified scale processing $U_{i j}$ is:

$$
\left\{\begin{array}{l}
U_{i j}=\left[u_{i j}(a), u_{i j}(b)\right] \\
u_{i j}(a)=\left(v_{i j}(a)-\min _{1 \leq i \leq m}\left(V_{i j}\right)\right) /\left(\max _{1 \leq i \leq m}\left(V_{i j}\right)-\min _{1 \leq i \leq m}\left(V_{i j}\right)\right) \\
u_{i j}(b)=\left(v_{i j}(b)-\min _{1 \leq i \leq m}\left(V_{i j}\right)\right) /\left(\max _{1 \leq i \leq m}\left(V_{i j}\right)-\min _{1 \leq i \leq m}\left(V_{i j}\right)\right)
\end{array}\right.
$$


If the indicator is a negative indicator, the value of the unified scale processing $U_{i j}$ is:

$$
\left\{\begin{array}{l}
U_{i j}=\left[u_{i j}(a), u_{i j}(b)\right] \\
u_{i j}(a)=\left(\max _{1 \leq i \leq m}\left(V_{i j}\right)-v_{i j}(b)\right) /\left(\max _{1 \leq i \leq m}\left(V_{i j}\right)-\min _{1 \leq i \leq m}\left(V_{i j}\right)\right) \\
u_{i j}(b)=\left(\max _{1 \leq i \leq m}\left(V_{i j}\right)-v_{i j}(a)\right) /\left(\max _{1 \leq i \leq m}\left(V_{i j}\right)-\min _{1 \leq i \leq m}\left(V_{i j}\right)\right)
\end{array}\right.
$$

In particular, when $v_{i j}(a)=v_{i j}(b), V_{i j}$ is the precise value, and its unified scaling process is a special case of the interval value unified scaling process.

\subsection{Indicator weight acquisition based on entropy weight method}

It can be seen from the construction process of the evaluation system that the evaluation system has the multi-level structural characteristics, and the evaluation indicators of different levels generally have different contributions to the evaluation results. In order to make the music course teaching level evaluation have higher reliability, the weights of different evaluation indicators should be calculated and analyzed. Entropy weight method has good objectivity and practicality [14-21], therefore, this paper adopts entropy weight method to obtain the weights of the evaluation indicators for the teaching level of music courses, and the specific realization process is as follows.

First of all, after the evaluation indicator value ${ }^{U_{i j}}$ had been subject to the unified scale processing, it took $U_{i j}^{*}=\left(u_{i j}(a)+u_{i j}(b)\right) / 2$, then the entropy weight method evaluation matrix $\boldsymbol{U}^{*}$ of the music course teaching level evaluation indicators can be established as:

$$
\boldsymbol{U}^{*}=\left[U_{i j}\right]_{m \times n}
$$

Secondly, based on the evaluation matrix $U^{*}$, the information entropy $e_{j}$ of the jth evaluation indicator can be obtained as:

$$
e_{j}=-\frac{1}{\ln m} * \sum_{i=1}^{m}\left(\left(\frac{U_{i j}^{*}}{\sum_{i=1}^{m} U_{i j}^{*}}\right) * \ln \left(\frac{U_{i j}^{*}}{\sum_{i=1}^{m} U_{i j}^{*}}\right)\right)
$$


Then, the weight ${ }^{w_{j}}$ of the $\mathrm{j}$-th evaluation indicator can be obtained as:

$$
w_{j}=\frac{\left(1-e_{j}\right)}{\sum_{j=1}^{n}\left(1-e_{j}\right)}
$$

Finally, the weight sequence $\mathrm{W}$ of the evaluation indicators of the music course teaching level can be obtained as follows:

$$
\boldsymbol{W}=\left\{w_{1}, w_{2}, \cdots, w_{j}, \cdots, w_{n-1}, w_{n}\right\}^{T}
$$

\subsection{Multi-attribute fuzzy decision-making analysis}

Based on the obtained evaluation indicator value ${ }^{U_{i j}}$ after the unified scale processing, the gray positive ideal interval $U_{j}^{\wedge}$ of the $\mathrm{j}$-th evaluation indicator can be constructed as:

$$
\left\{\begin{array}{l}
U_{j}^{\wedge}=\left[u_{j}^{\wedge}(a), u_{j}^{\wedge}(b)\right] \\
u_{j}^{\wedge}(a)=\max _{1 \leq i \leq m}\left(u_{i j}(a)\right) \\
u_{j}^{\wedge}(b)=\max _{1 \leq i \leq m}\left(u_{i j}(b)\right)
\end{array}\right.
$$

The grey negative ideal interval $U_{j}^{\vee}$ of the j-th evaluation indicator is:

$$
\left\{\begin{array}{l}
U_{j}^{\vee}=\left[u_{j}^{\vee}(a), u_{j}^{\vee}(b)\right] \\
u_{j}^{\vee}(a)=\min _{1 \leq i \leq m}\left(u_{i j}(a)\right) \\
u_{j}^{\vee}(b)=\min _{1 \leq i \leq m}\left(u_{i j}(b)\right)
\end{array}\right.
$$

According to the fuzzy system theory [22-27], for the i-th object to be evaluated, the Euclidean distances $D_{i j}^{\wedge}$ and $D_{i j}^{\vee}$ between it and the gray positive ideal interval $U_{j}^{\wedge}$ and the grey negative ideal interval $U_{j}^{\vee}$ with respect to the j-th evaluation indicator are:

$$
D_{i j}^{\wedge}=\sqrt{\frac{\left(u_{j}^{\wedge}(a)-u_{i j}(a)\right)^{2}+\left(u_{j}^{\wedge}(b)-u_{i j}(b)\right)^{2}}{2}}
$$




$$
D_{i j}^{\vee}=\sqrt{\frac{\left(u_{j}^{\vee}(a)-u_{i j}(a)\right)^{2}+\left(u_{j}^{\vee}(b)-u_{i j}(b)\right)^{2}}{2}}
$$

According to the gray system theory [28-31], for the i-th object to be evaluated, the gray correlation coefficients $\delta_{i j}^{\wedge}$ and $\delta_{i j}^{\vee}$ between it and the gray positive ideal interval $U_{j}^{\wedge}$ and the grey negative ideal interval $U_{j}^{\vee}$ with respect to the $\mathrm{j}$-th evaluation indicator are:

$$
\begin{gathered}
\delta_{i j}^{\wedge}=\frac{\min _{1 \leq i \leq m} \min _{1 \leq j \leq n}\left|D_{i j}^{\wedge}\right|+\beta \max _{1 \leq i \leq m} \max _{1 \leq j \leq n}\left|D_{i j}^{\wedge}\right|}{\left|D_{i j}^{\wedge}\right|+\beta \max _{1 \leq i \leq m} \max _{1 \leq j \leq n}\left|D_{i j}^{\wedge}\right|} \\
\delta_{i j}^{\vee}=\frac{\min _{1 \leq i \leq m} \min _{1 \leq j \leq n}\left|D_{i j}^{\vee}\right|+\beta \max _{1 \leq i \leq m} \max _{1 \leq j \leq n}\left|D_{i j}^{\vee}\right|}{\left|D_{i j}^{\vee}\right|+\beta \max _{1 \leq i \leq m} \max _{1 \leq j \leq n}\left|D_{i j}^{\vee}\right|}
\end{gathered}
$$

Combining with the weight ${ }^{w_{j}}$ of the j-th evaluation indicator obtained based on the entropy weight method, for the i-th object to be evaluated, the weighted gray correlation degrees $\gamma_{i}^{\wedge}$ and $\gamma_{i}^{\vee}$ between it and the gray positive ideal interval $U_{j}^{\wedge}$ and the grey negative ideal interval $U_{j}^{\vee}$ are:

$$
\begin{aligned}
& \gamma_{i}^{\wedge}=\sum_{j=1}^{n}\left(w_{j} * \delta_{i j}^{\wedge}\right) \\
& \gamma_{i}^{\vee}=\sum_{j=1}^{n}\left(w_{j} * \delta_{i j}^{\vee}\right)
\end{aligned}
$$

Thus, the comprehensive gray correlation degree $\gamma_{i}$ of the i-th evaluation object can be obtained as:

$$
\gamma_{i}=1 /\left(1+\frac{\left(\gamma_{i}^{\vee}\right)^{2}}{\left(\gamma_{i}^{\wedge}\right)^{2}}\right)
$$

$\gamma^{\Theta}$ represents the evaluation threshold of music course teaching level, if the comprehensive gray correlation degree $\gamma_{i}$ of the i-th evaluation object is greater than $\gamma^{\Theta}$, it indicates that the object has a high teaching level, otherwise its teaching level is unqualified and needs to be improved. 


\section{$5 \quad$ Suggestions and Measures for the Improvement of Music Course Teaching Level}

If the music course teaching level of an evaluation object cannot meet the set threshold, targeted measures need to be taken to improve the music course teaching level from the following aspects:

\subsection{Increase investment in music teaching resources and enhance basic guarantees for music teaching}

Increasing the investment in music teaching resources includes three dimensions: human resource input, financial resource input and material resource input. The input of human resources in music teaching can be divided into two parts: the input of music teaching managerial staffs and the input of music teachers. The focus is to well allocate the professional talents based on the job requirements of music course teaching, especially the job positions that are in shortage of service talents for music course teaching, so that they could provide high-quality teaching services for the smooth implementation of music course teaching. The input of financial resource refers to the financial investment in music teaching activities, including government educational appropriations, self-collected funds by schools, and school-enterprise cooperation, etc. These inputs can be used for the construction of software and hardware facilities of music course teaching. The input of material resource refers to the material supports and reserves provided for the teaching of music courses in the purpose of ensuring the normality and smoothness of teaching order in music courses. It can be seen that by increasing the investment in the above-mentioned aspects, good basic guarantees could be provided for the teaching of music courses.

\subsection{Actively introduce senior talents and construct high-level music faculty}

Music course teaching requires to constantly supplement and reserve new talents, so that a gradient talent-growth structure could be formed for the construction of music faculty, thereby forming a professional faculty team with good sustainable development ability and competitiveness that can play an indispensable supportive role in promoting the teaching level of music courses. On the one hand, actively introducing senior music talents can supplement the possible loss of the outflow of faculty members and add fresh blood for music courses, so that the music faculty can maintain the circulation of talents, which is more conducive to the upgrade of the talent structure of the faculty; on the other hand, it can expand the professional perspective of the music faculty, closely combining with the current hotspots in the teaching of music majors and keeping up with the development status of music courses, thereby providing good references and guidance for the development of music course teaching. 


\subsection{Well plan the teaching of music courses and enhance the competitiveness of teaching materials}

According to previous discussion, music teaching is a complex system project, which not only needs to consider the teaching goals, syllabus, teaching schemes, teaching tasks, teaching plans and teaching results of the music courses, but also needs to form a series of excellent music courses with professional features. How can the excellent music courses have good adaptability? This study believes that works of two aspects should be done well, one is to formulate good curriculum planning of music courses, that is, make systematic, scientific and reasonable arrangements for music courses based on the specific situation of music course teaching and the students' characteristics, promote the implementation of music teaching tasks in a targeted manner, so that the implementation links of music teaching are more in line with the learning requirements of music students; the other is to well compile the professional teaching materials for music courses; in terms of the current actual situations, some music course textbooks are out of date and can hardly meet the requirements of modern quality-oriented education; moreover, due to the rapid development of information technology, the music knowledge types are becoming increasingly diversified and the dissemination speed is very fast, which makes it difficult for music majors to choose suitable music course textbooks, therefore, compiling representative music course textbooks will help students choose suitable learning objects, especially form a systematic excellent music course system, which can provide an effective guarantee for students' learning effect.

\subsection{Strengthen the training of music teachers' professional abilities and improve the teaching effect of music courses}

Classroom teaching is the main form of music teaching, so improving the classroom teaching effect is an important link in the improvement of the teaching level of music courses, and it's also an indispensable part for the improvement of the teaching quality and efficiency of music teaching. To improve the teaching effect of music classroom teaching, this paper holds that the most important thing is to strengthen the professional ability training of music teachers, and such training includes not only the music teachers' professional literacy, but also their understandings of the teaching mode, teaching concept, teaching tools, teaching methods, teaching content and teaching plan of the music courses; only by enhancing the comprehensive qualities of music teachers from both aspects of their thinking and professional literacy, can we more effectively ensure the improvement of the teaching quality of music classroom teaching. To this end, increasing the professional training opportunities and practice time for music teachers is a necessary move for enhancing the academic communication ability of music teachers. 


\subsection{Perfect the management system of music teaching and enrich the diversity of music teaching approaches}

The teaching management system of music courses is the basic guarantee for the smooth implementation of music course teaching. The formulation of the teaching management system of music courses needs to take into account various factors such as individual teachers, individual students and individual managerial staffs, and the formulation principle is that the system should be able to ensure the orderly and fluent implementation of teachers' teaching activities, students' learning activities, and the managerial staffs' managing activities, ensure the smooth implementation of the teaching plan of music courses, and ensure the effective improvement of the teaching level of music courses. Due to the continuous development of modern education technology, the application of intelligent technology has become more and more extensive, one merit is that it has an impact on the improvement of teaching quality to a certain extent, therefore, in the implementation process of music teaching management system, an important link is to ensure the diversity of the teaching approaches of music courses. This paper holds that in the formulation process of the music teaching management system, more consideration should be given to the supporting role of intelligent education technology in music course teaching, and more attention should be paid to the use of intelligent technology to support music course teaching, so that music students' intelligent learning could be improved to the greatest extent, and thereby enhancing their learning interests and autonomous learning abilities.

\subsection{Perfect the industry-university-research mechanism of music teaching and expand the social service function of music teaching}

The industry-university-research mechanism is an integrated teaching mode with prominent application effect in modern higher education. Through the combination of industries, school works and scientific research, it could achieve the absorption effect of the mutual supplement, mutual assist, and mutual support of students' professional learning. This paper holds that the learning of music is not just the reserve, absorption and learning of the professional knowledge, it is the same as the learning of other professional courses, and it should be carried out based on social service, that is to say, the learning and creation of music come from the society, and they must serve the society, the teaching of music courses must be closely integrated with the development of the society. As a comprehensive mode that connects society, schools, and scientific research, the industry-university-research mechanism can better reflect the essence of music course teaching, better meet the requirements of social development, and it makes the students' learning closer to their job orientations. Therefore, the industry-university-research mechanism is more conducive to triggering the learning interests and motivation of music students, as well as improving the teaching level of music courses. 


\section{Conclusion}

The main research results of this paper are reflected in the following aspects:

1. This paper analyzed the relevant influencing factors in the implementation process of music course teaching, and proposed a few suggestions and measures for improving the teaching level of music courses, which is of good guiding significance and reference value for improving the teaching quality of music courses.

2. This paper constructed an improved music course teaching level system, which can make the evaluation process of the teaching level of music courses more comprehensive, integrated, and systematic, so that the evaluation results of the teaching level of music courses could be more reliable.

3. This paper gave a music course teaching level evaluation model that integrated the entropy weight method, the fuzzy system theory and the grey system theory; then the quantitative analysis of the evaluation of music course teaching level had been achieved, which made the evaluation results of the teaching level of music courses more accurate.

\section{$7 \quad$ References}

[1] Chao-Fernandez, R., Román-García, S., \& Chao-Fernandez, A. (2017). Analysis of the use of ICT through music interactive games as educational strategy. Procedia-Social and Behavioral Sciences, 237: 576-580. https://doi.org/10.1016/j.sbspro.2017.02.109

[2] Bújez, A.V., \& Mohedo, M.T.D. (2012). New challenges for music studies in higher education. Procedia-Social and Behavioral Sciences, 69: 571-578. https://doi.org/10.1016/ j.sbspro.2012.11.448

[3] Li, Y. (2019). Modelling of music learning process based on knowledge sharing, International Journal of Emerging Technologies in Learning, 14(23), 208-220. https://doi. org/10.3991/ijet.v14i23.12257

[4] Lee, A., \& Jen, Y.H. (2015). Interactive whiteboard integration into music teaching and learning: Preschool children as a case study. Procedia-Social and Behavioral Sciences, 177: 449-458. https://doi.org/10.1016/j.sbspro.2015.02.394

[5] Yang, L. (2016). Discussion on the application of process evaluation in college music teaching evaluation. Huang $\mathrm{He}$ Zhi Sheng, (2): 42-42. https://doi.org/10.19340 /j.cnki.hhzs.2016.02.031

[6] Ye, P.J., Qian, J., \& Wan, Y.L. (2014). Discussion on the development of innovative ability in students' music practice. Journal of Chifeng University (Natural Science Edition), (8): 251-252. https://doi.org/10.3969/j.issn.1673-260X.2014.08.103

[7] Firrincieli, A. (2017). Maieutic: a teaching and learning approach. As applied to western music. Procedia-Social and Behavioral Sciences, 237: 1520-1525. https://doi.org/10.1016/ j.sbspro.2017.02.239

[8] Marjanen, K., \& Cslovjecsek, M. (2014). Transversal learning through music in the teaching profession. Procedia-Social and Behavioral Sciences, 112: 1046-1055. https://doi. org/10.1016/j.sbspro.2014.01.1268

[9] Wang, J.R. (2016). Research on the music normal education teaching under the concept of new curriculum standard. Survey of Education, 5(5): 105-106. http://dx.doi.org/10. $\underline{\text { 3969/j.issn.2095-3712(s).2016.03.044 }}$ 
[10] Xu, S. (2016). Case study on music teaching evaluation system. Huang He Zhi Sheng, (3): $42-42$.

[11] Sydykova, R., Kakimova, L., Ospanov, B., Tobagabylova, A., \& Kuletova, U. (2018). A conceptual approach to developing the creativity of a music teacher in modern educational conditions. Thinking Skills and Creativity, 27: 160-166. https://doi.org/10.1016/j.tsc.2017. $\underline{12.007}$

[12] Kuloglu, N. (2015). Teaching strategies learning through art: music and basic design education. Procedia-Social and Behavioral Sciences, 182: 395-401. https://doi.org/10.10 16/j.sbspro.2015.04.802

[13] Pan, R. (2014). Perplexity and reflection on the evaluation of general music teaching in colleges and universities in China. Journal of Tianjin Academy of Educational Science, (5): 24-26. https://doi.org/10.3969/j.issn.1671-2277.2014.05.007

[14] Fedajev, A., Stanujkic, D., Karabašević, D., Brauers, W.K., \& Zavadskas, E.K. (2020). Assessment of progress towards "Europe 2020" strategy targets by using the MULTIMOORA method and the Shannon Entropy Index. Journal of Cleaner Production, 244: 118895. https://doi.org/10.1016/j.jclepro.2019.118895

[15] Karagiannis, R., \& Karagiannis, G. (2020). Constructing composite indicators with Shannon entropy: The case of Human Development Index. Socio-Economic Planning Sciences, 70: 100701. https://doi.org/10.1016/j.seps.2019.03.007

[16] Shao, Z. H., Zhong, Z. X., Lin, W. Z. (2018). Reliability analysis and matpower simulation of IEEE14 node based on mixed entropy measure. European Journal of Electrical Engineering, 20(5-6), 573-588. https://doi.org/10.3166/ejee.20.573-588

[17] Cavallaro, F., Zavadskas, E.K., Streimikiene, D., \& Mardani, A. (2019). Assessment of concentrated solar power (CSP) technologies based on a modified intuitionistic fuzzy topsis and trigonometric entropy weights. Technological Forecasting and Social Change, 140: 258-270. https://doi.org/10.1016/j.techfore.2018.12.009

[18] Murugan, S., Kulanthaivel, G., Ulagamuthalvi, V. (2019). Selection of test case features using fuzzy entropy measure and random forest. Ingénierie des Systèmes d'Information, 24(3), 261-268. https://doi.org/10.18280/isi.240306

[19] Tuğal, İ., \& Karc1, A. (2019). Comparisons of Karc1 and Shannon entropies and their effects on centrality of social networks. Physica A: Statistical Mechanics and its Applications, 523: 352-363. https://doi.org/10.1016/j.physa.2019.02.026

[20] Velázquez-Martinez, O., Kontomichalou, A., Santasalo-Aarnio, A., Reuter, M., Karttunen, A.J., Karppinen, M., \& Serna-Guerrero, R. (2020). A recycling process for thermoelectric devices developed with the support of statistical entropy analysis. Resources, Conservation and Recycling, 159: 104843. https://doi.org/10.1016/j.resconrec.2020.104843

[21] Ouchtati, S., Chergui, A., Mavromatis, S., Aissa, B., Rafik, D., Sequeira J. (2019). Novel method for brain tumor classification based on use of image entropy and seven $\mathrm{Hu}$ 's invariant moments. Traitement du Signal, 36(6), 483-491. https://doi.org/10.18280/ts.36 $\underline{0602}$

[22] Boukezzoula, R., Coquin, D., Nguyen, T.L., \& Perrin, S. (2018). Multi-sensor information fusion: Combination of fuzzy systems and evidence theory approaches in color recognition for the NAO humanoid robot. Robotics and Autonomous Systems, 100: 302-316. https:// doi.org/10.1016/j.robot.2017.12.002

[23] Sánchez, A.D.B., \& Lavor, C. (2020). On the estimation of unknown distances for a class of Euclidean distance matrix completion problems with interval data. Linear Algebra and its Applications, 592: 287-305. https://doi.org/10.1016/j.laa.2020.01.036 
[24] Patel, S. P., \& Upadhyay, S. H. (2020). Euclidean Distance based Feature Ranking and Subset Selection for Bearing Fault Diagnosis. Expert Systems with Applications, 154: 113400. https://doi.org/10.1016/j.eswa.2020.113400

[25] Li, Z.L., Zhou, Y., Bao, R. (2019). An image classification method based on optimized fuzzy bag-of-words model. Traitement du Signal, 36(3), 239-244. https://doi.org/10.18280/ ts.360306

[26] Guo, J., Liu, Y., Cheng, X. J., Yan, H., Xu, Y. Q. (2018). A novel prediction model for the degree of rescue safety in mine thermal dynamic disasters based on fuzzy analytical hierarchy process and extreme learning machine. International Journal of Heat and Technology, 36(4), 1336-1342. https://doi.org/10.18280/ijht.360424

[27] Marwan, H., Ali, A. (2019). Experts' consensus to identify elements of career management competencies in Work-Based Learning (WBL) program using fuzzy delphi analysis, International Journal of Emerging Technologies in Learning, 14(20), 73-86. https://doi. org/10.3991/ijet.v14i20.11461

[28] Keleştemur, O., \& Arıcı, E. (2020). Analysis of some engineering properties of mortars containing steel scale using Taguchi based grey method. Journal of Building Engineering, 29: 101015. https://doi.org/10.1016/j.jobe.2019.101015

[29] Pandya, V.J., \& Rathod, P.P. (2020). Optimization of mechanical properties of green composites by gray relational analysis. Materials Today: Proceedings, 27: 19-22. https:// doi.org/10.1016/j.matpr.2019.08.166

[30] Kanchana, J., Prasath, V., \& Krishnaraj, V. (2019). Multi response optimization of process parameters using grey relational analysis for milling of hardened Custom 465 steel. Procedia Manufacturing, 30: 451-458. https://doi.org/10.1016/j.promfg.2019.02.064

[31] Mazarbhuiya, R.M., \& Rahang, M. (2020). Surface modification of aluminium and its parametric optimization using grey relational analysis. Materials Today: Proceedings, 26 : 1594-1597. https://doi.org/10.1016/j.matpr.2020.02.327

\section{Author}

Liuqing Yang, (1986.06-), graduated from Henan University with a master's degree in art. She is currently working as a lecturer at Henan Radio \& Television University. Her research directions include music functions, music talent training, music teaching methods, etc. In terms of scientific research: she has published 9 papers, participated in editing 2 textbooks, 1 book, presided over 4 department-level projects and has 1 utility model patent. In terms of teaching: she won the provincial second prize in the teaching skills competition and has guided students to participate in provincial competitions and won many awards.

Article submitted 2020-07-31. Resubmitted 2020-08-29. Final acceptance 2020-08-30. Final version published as submitted by the authors. 